\title{
One-pot synthesis of 1,3,5-triazine-2,4-dithione derivatives via three-component reactions
}

\author{
Gui-Feng Kang ${ }^{*}$ and Gang Zhang ${ }^{2}$
}

\author{
Full Research Paper \\ Address: \\ ${ }^{1}$ School of Pharmaceutical Sciences, Capital Medical University, \\ Beijing 100069, China and ${ }^{2}$ State Key Laboratory of Bioactive \\ Substances and Function of Natural Medicine, Institute of Materia \\ Medica, Peking Union Medical College and Chinese Academy of \\ Medical Sciences, Beijing 100050, China \\ Email: \\ Gui-Feng Kang* - guifengkang@ccmu.edu.cn \\ ${ }^{*}$ Corresponding author \\ Keywords: \\ aldehydes; multicomponent reactions; nitrogen heterocycles; thiourea; \\ triazinethiones
}

\author{
Beilstein J. Org. Chem. 2020, 16, 1447-1455. \\ doi:10.3762/bjoc. 16.120 \\ Received: 04 May 2020 \\ Accepted: 04 June 2020 \\ Published: 24 June 2020 \\ Associate Editor: B. Nay \\ (C) 2020 Kang and Zhang; licensee Beilstein-Institut. \\ License and terms: see end of document.
}

\begin{abstract}
A catalyst-free one-pot synthetic methodology was developed for the preparation of 1,3,5-triazine-2,4-dithione derivatives through three-component reactions of arylaldehydes, thiourea, and orthoformates. The procedure tolerated a diverse range of arylaldehydes and orthoformates and provided a rapid entry to a variety of 4-aryl-6-(alkylthio)-3,4-dihydro-1,3,5-triazine-2(1H)-thiones (29 examples). The synthetic strategy relies on the dual role of thiourea in the cyclization with the aldehydes and the alkylation via an intermediate imidate formation. The structures of 1,3,5-triazine-2,4-dithione derivatives were characterized by spectroscopic techniques as well as by single crystal X-ray diffraction.
\end{abstract}

\section{Introduction}

The construction of nitrogen-containing heterocycles is one of the most prolific areas in organic chemistry that has drawn considerable attention from chemists due to their widespread occurrence in a variety of natural products [1-4], chemical materials [5,6], and medication [7]. Among the vast array of nitrogencontaining heterocyclic compounds, triazines and substituted triazines are of particular utility in drug discovery because of their broad potential biological activities [8,9]. Besides, triazinethiones also played important roles in the construction of an array of pharmacologically important compounds (Figure 1), comprising anticancer [10,11], antimicrobial [12], antiviral agents [13,14], and eosinophilia inhibitors [15]. Therefore, it is highly desirable to develop efficient and practical synthetic methods for triazinethione architectures and to expand the structure diversity of this class of compounds for medicinal chemistry demands.

Several methods were reported for the synthesis of triazinethione analogs. One of the most popular methods involved the reaction of a carboximidamide [16], or urea [17] 
<smiles>CCCCCCSc1nc2n(c(=S)n1)CCN2C(=S)NC(=O)c1ccccc1</smiles>

anticancer agent<smiles></smiles>

antimicrobial agent<smiles>Cc1nc(C)n2c(=S)[nH]cnc12</smiles>

antiviral agent

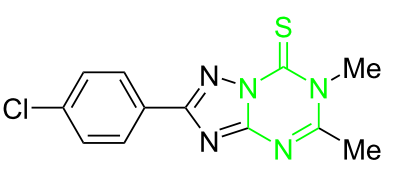

eosinophilia inhibitor

Figure 1: Selected examples of triazinethione-containing bioactive compounds.

with isothiocyanates. The $\mathrm{C}=\mathrm{S}$ bond in the latter is highly polar, with the carbon atom always positive and therefore being susceptible to nucleophilic attack. The resulting substituted thioureas underwent a cyclization reaction providing the desired triazinethiones (Scheme 1a and 1b). However, this method required the preparation of the starting isothiocyanates, which limited its synthetic applications. In another method, triazinethione derivatives were synthesized through the sulfidation of triazine using phosphorus oxychloride and hydrogen sulfide (Scheme 1c) [18]. This strategy required harsh reaction conditions and also suffered from an awful smell. Therefore, the development of facile and environmentally benign methodologies for the generation of structurally diverse triazinethione derivatives is still challenging in organic synthetic chemistry and medicinal chemistry.

Multicomponent reactions (MCRs) gained much interest among synthetic organic chemists as well as in combinatorial chemistry and drug discovery as versatile tools for the construction of different biologically active compounds by combining three or

previous works:

(a)<smiles>[R]C(N)=NC(=S)N=C([R])N</smiles><smiles>[R]C(=O)N=C=S</smiles>

(c)

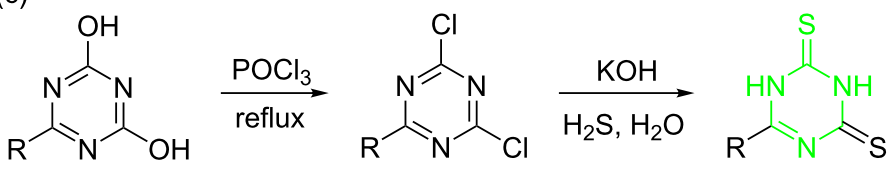

this work: one-pot catalyst-free multicomponent reactions

(d)<smiles>[R][R]OC(O[R])O[R]</smiles><smiles>c1ccccc1</smiles>
$80^{\circ} \mathrm{C}, 5 \mathrm{~h}$<smiles>[R]SC1=NC(c2ccccc2)NC(=S)N1</smiles> 
more starting materials into a single product in one convergent chemical step [19-23]. Among multicomponent reactions, aldehydes have emerged as one of the most useful class of molecules. They are quite flexible as possible starting substrates, and through cyclization reactions, can lead to a variety of complex molecules, allowing a wide exploration of scaffolds and substituents diversity [24-28]. In this regard, the use of simple thiourea as an inexpensive thiocarbonyl group source in the multicomponent reaction with aldehydes and other reactive intermediates for the preparation of various triazinethione derivatives by independently varying the individual components thus represents a significant extension in this area. On the other hand, trialkyl orthoformates are versatile building blocks in organic synthesis, capable of constructing acyl derivatives [29-33] and ether derivatives [34-36] through acylation and alkylation under the appropriate conditions.

In view of what was explained above, and as a result of our interest in developing novel multicomponent reactions to access diverse triazinethione derivatives, we recently synthesized a series of 4-aryl-6-(alkylthio)-3,4-dihydro-1,3,5-triazine-2(1H)thiones from aldehydes, thiourea and suitable orthoformates. This strategy was straightforward and the reaction conditions were mild (Scheme 1d). Herein we report the details of this effort.

\section{Results and Discussion}

We explored the synthesis of 1,3,5-triazine-2,4-dithione derivatives by carrying out a set of experiments using benzaldehyde (1a, 1.0 equiv), thiourea (2, 1.0 equiv), and trimethyl orthoformate (3a, 1.0 equiv) as the model reaction (Table 1 ). The combination of these substrates in the absence of any extra reaction medium did not provide any product at room temperature, even after 12 hours (Table 1, entry 1). Interestingly, when the model reaction was repeated using DMF as the solvent trace amounts of 1,1'-(phenylmethylene)bis(thiourea) (4) were observed after stirring $12 \mathrm{~h}$ at room temperature (Table 1, entry 2). An increase in the yield of product $\mathbf{4}$ was observed when the reaction time was extended to $24 \mathrm{~h}$ (Table 1, entry 3 ). Changing the solvent to either hexafluoroisopropanol (HFIP) or 1,4-dioxane did not provide higher yields under the same conditions (Table 1, entries 4 and 5). However, when the reaction temperature was raised to $50{ }^{\circ} \mathrm{C}$ in DMF as solvent, the yield of compound $\mathbf{4}$ decreased (Table 1, entry 6). On the basis of these results, we suggested that upon heating, the inherent reactivity of the intermediate 4 led to a decomposition. In another experiment, the same reaction was tested at $80{ }^{\circ} \mathrm{C}$ for $1 \mathrm{~h}$ and intermediate 4 in addition to formylthiourea (5) were formed in low yields (Table 1, entry 7$)$. When the reaction time was extended to $5 \mathrm{~h}$, the desired three component product 6-(methylthio)-4-phenyl-3,4dihydro-1,3,5-triazine-2(1H)-thione (6aa) was obtained in $22 \%$

Table 1: Optimization of reaction conditions. ${ }^{a}$

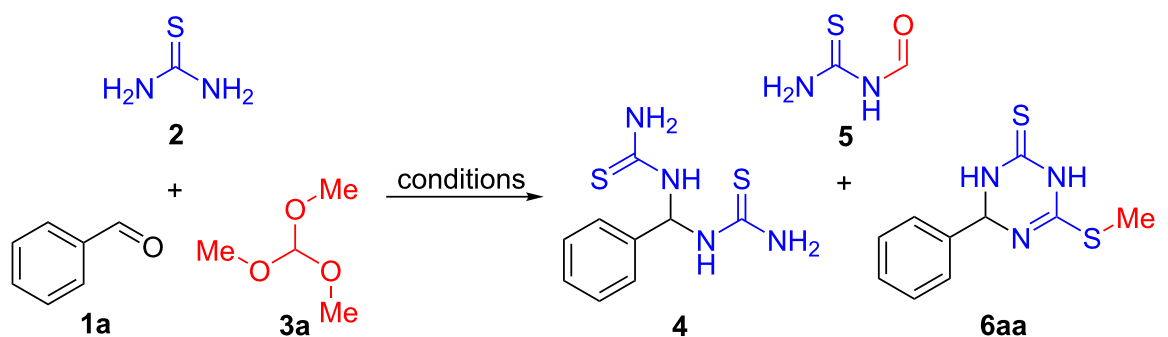

\begin{tabular}{|c|c|c|c|c|c|c|}
\hline \multirow[t]{2}{*}{ entry } & \multirow[t]{2}{*}{ solvent } & \multirow[t]{2}{*}{$T\left({ }^{\circ} \mathrm{C}\right)$} & \multirow[t]{2}{*}{ time $(\mathrm{h})$} & \multicolumn{3}{|c|}{ yield $(\%)^{b}$} \\
\hline & & & & 4 & 5 & 6aa \\
\hline 1 & none & $\mathrm{rt}$ & 12 & 0 & 0 & 0 \\
\hline 2 & DMF & $\mathrm{rt}$ & 12 & trace & 0 & 0 \\
\hline 3 & DMF & $\mathrm{rt}$ & 24 & 28 & 0 & 0 \\
\hline 4 & HFIP & $\mathrm{rt}$ & 24 & 15 & 0 & 0 \\
\hline 5 & dioxane & $\mathrm{rt}$ & 24 & 20 & 0 & 0 \\
\hline 6 & DMF & 50 & 24 & 18 & 0 & 0 \\
\hline 7 & DMF & 80 & 1 & 20 & 8 & 0 \\
\hline 8 & DMF & 80 & 5 & 15 & 17 & 22 \\
\hline 9 & DMF & 100 & 5 & 10 & 25 & 16 \\
\hline
\end{tabular}

aReaction conditions: benzaldehyde ( $1.0 \mathrm{mmol}, 1.0$ equiv), thiourea ( $1.0 \mathrm{mmol}, 1.0$ equiv), trimethyl orthoformate ( $1.0 \mathrm{mmol}, 1.0$ equiv); ${ }^{b}$ yields refer to isolated yields. 
yield (Table 1, entry 8). However, increasing the temperature to $100{ }^{\circ} \mathrm{C}$ failed to enhance the reaction rate substantially (Table 1 , entry 9). In point of fact, higher temperatures lowered the product yield slightly, accompanied by some impurities.

Encouraged by the result shown in Table 1, entry 8, we further optimized the conditions at $80{ }^{\circ} \mathrm{C}$ in DMF as reaction medium by varying the amount of thiourea and trimethyl orthoformate (Table 2). Increasing the amount of thiourea (2) significantly increased the yield. If the ratio of $\mathbf{1 a} / \mathbf{2}$ was altered to $1: 2$, product 6aa was isolated in $73 \%$ yield (Table 2 , entry 1 ) and we observed that reactions carried out with an excess of 2 gave higher yields of the product (Table 2, entries 2-4). An excellent yield of $90 \%$ was achieved when 2.5 equiv of thiourea (2) were used (Table 2, entry3). Conversely, increasing the amount of $\mathbf{3 a}$ decreased the yield markedly (Table 2, entries 6-8), and we observed that the best result was obtained with 1.0 equiv of this component relative to $\mathbf{1 a}$ (Table 2 , entry 3 vs entries $5-8$ ).

Table 2: Optimization of the reaction conditions. ${ }^{a}$

\begin{tabular}{llll} 
& \\
\hline & & 30
\end{tabular}

aReaction conditions: benzaldehyde ( $1.0 \mathrm{mmol}, 1.0$ equiv), thiourea, trimethyl orthoformate, DMF $(1 \mathrm{~mL}), 80^{\circ} \mathrm{C}, 5 \mathrm{~h}$; byields refer to isolated yields.

Having established the optimal reaction conditions (Table 2, entry 3), we next investigated the generality of this multicomponent reaction with a wide range of aldehydes 1 together with thiourea (2) and trimethyl orthoformate (3a) (Scheme 2). The reaction carried out with 4-methylbenzaldehyde delivered the expected 6-(methylthio)-4-( $p$-tolyl)-3,4-dihydro-1,3,5-triazine$2(1 H)$-thione (6ba) in $92 \%$ yield, and this outcome was even better than that of treating the parent compound 1a analogously.
The steric environment surrounding aldehyde group markedly affected the reaction, as 3-methylbenzaldehyde (1c) and 2-methylbenzaldehyde (1d) provided products $6 \mathbf{c a}$ and $\mathbf{6 d a}$ in 72 and $48 \%$ yield, respectively. The reaction also worked well with other 4-alkylbenzaldehydes 1e and 1f, giving the expected products 6ea and 6fa in very good yields. We found benzaldehydes featuring other electron-donating groups such as methoxy (1g) and methylthio (1h) in the para-position of the aldehyde group were also applicable in the reaction, and provided products 6 ga and $6 \mathbf{h a}$ in still moderate yields.

When an electron-deficient aromatic aldehyde such as 4-phenylbenzaldehyde (1i) was used, the reaction effectively afforded product $6 \mathbf{i a}$ in $45 \%$ yield. Similarly, benzaldehydes having other electron-withdrawing groups such as cyano, nitro, and trifluoromethyl they smoothly took part in the three-component reaction and provided the desired products $6 \mathbf{j a - n a}$ in moderate yields. It is noteworthy that benzaldehydes containing a halogen atom such as fluorine, chlorine, bromine, and iodine in the para and meta-positions were also compatible with the reaction conditions and yielded the corresponding products (6oa-va, 48-92\%), allowing for further functionalization through subsequent transition-metal-catalyzed coupling reactions.

Intriguingly, it was found that compounds with bicycloaryl and heteroaryl ring systems were also viable substrates, affording the desired products $6 \mathbf{w a}-\mathbf{y a}$ in $65-81 \%$ yields. The possibility of using aliphatic aldehydes in place of aromatic aldehydes was investigated for $\mathbf{2}$ and 3a. Fortunately, the reactions carried out with isobutyraldehyde (1z) yielded $31 \%$ of the isopropyl-functionalized 6-(methylthio)-3,4-dihydro-1,3,5-triazine-2(1H)thione (6za). However, no product was detected starting from paraformaldehyde and paraldehyde. Presumably, this result could be either due to the aliphatic aldehydes' lower reactivity with thiourea to generate the intermediate imines undergoing ring-closure and subsequent alkylation, and/or due to the instability of the imines formed.

In order to further explore the substrate scope of this multicomponent reaction, next we wanted to use other orthoformates. Interestingly, under the similar reaction conditions triethyl orthoformate (3b), tripropyl orthoformate (3c), and tributyl orthoformate (3d) provided the corresponding products similarly to trimethyl orthoformate and the results are summarized in Scheme 3.

To assess the scalability of the multicomponent reaction, a $10 \mathrm{mmol}$ scale synthesis of 6-(methylthio)-4-phenyl-3,4dihydro-1,3,5-triazine-2(1H)-thione (6aa) was conducted under the optimized conditions and the product was obtained in $87 \%$ 


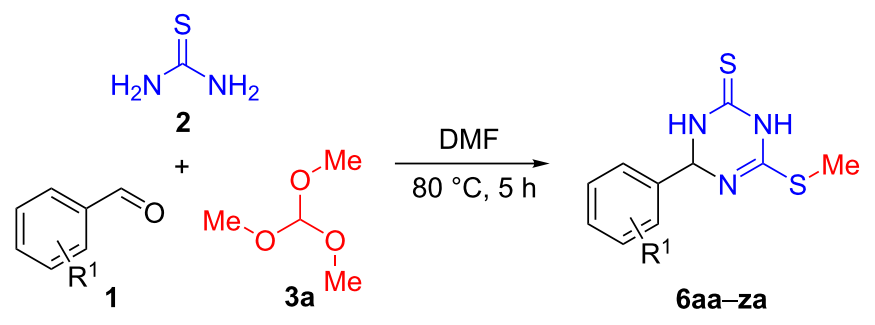<smiles>CSC1=NC(c2ccccc2)NC(=S)N1</smiles>

6aa, $90 \%$<smiles>CSC1=NC(c2ccc(-c3ccccc3)cc2)NC(=S)N1</smiles>

6ia, $45 \%$<smiles>[R]C1=NC(c2ccc([R])cc2)NC(=S)N1</smiles>

$\mathrm{R}=\mathrm{F}, \mathbf{6 0 a}, 85 \%$

$\mathrm{R}=\mathrm{Cl}, 6 \mathrm{pa}, 92 \%$

$\mathrm{R}=\mathrm{Br}, 6 \mathrm{qa}, 87 \%$

$\mathrm{R}=\mathrm{I}, \mathbf{6 r a}, 52 \%$<smiles>[R]c1ccccc1C1N=C(SC)NC(=S)N1</smiles>

$\mathrm{R}=4-\mathrm{Me}, \mathbf{6 b a}, 92 \%$

$\mathrm{R}=3-\mathrm{Me}, \mathbf{6 c a}, 72 \%$ $\mathrm{R}=2-\mathrm{Me}, 6 \mathrm{da}, 48 \%$<smiles>[R]c1cccc(C2N=C(SC)NC(=S)N2)c1</smiles>

$\mathrm{R}=4-\mathrm{NO}_{2}, 6 \mathrm{ja}, 44 \%$ $\mathrm{R}=3-\mathrm{NO}_{2}, \mathbf{6 k a}, 48 \%$<smiles>[R]c1cccc(C2N=C(SC)NC(=S)N2)c1</smiles>

$\mathrm{R}=\mathrm{F}, \mathbf{6 s a}, 78 \%$

$\mathrm{R}=\mathrm{Cl}, \mathbf{6 t a}, 82 \%$

$\mathrm{R}=\mathrm{Br}$, 6ua, $76 \%$

$\mathrm{R}=\mathrm{I}, \mathbf{6 v a}, 48 \%$

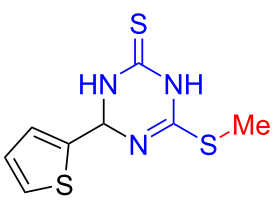

6ya, $65 \%$<smiles>[R]C1=NC(c2ccc([R])cc2)NC(=S)N1</smiles>

$\mathrm{R}=\mathrm{Et}, \mathbf{6 e a}, 90 \%$

$\mathrm{R}=\mathrm{iPr}, \mathbf{6 f a}, 89 \%$<smiles>[R]c1ccccc1C1N=C(SC)NC(=S)N1</smiles>

$\mathrm{R}=4-\mathrm{CF}_{3}, 6 \mathbf{a}, 53 \%$

$\mathrm{R}=3-\mathrm{CF}_{3}, 6 \mathrm{ma}, 57 \%$<smiles>COC1=NC(c2ccc3ccccc3c2)NC(=S)N1</smiles>

6wa, $75 \%$

$6 \times 2 a, 81 \%$

6 na, $47 \%$<smiles>[R]CS1=NC(c2ccc([R])cc2)NC(=S)N1</smiles>

$\mathrm{R}=$ OMe, 6 ga, $70 \%$

$\mathrm{R}=\mathrm{SMe}, \mathbf{6 h a}, 70 \%$<smiles>CSC1=NC(c2ccc(C#N)cc2)NC(=S)N1</smiles><smiles>CSC1=NC(c2ccco2)NC(=S)N1</smiles><smiles>CSC1=NC(C(C)C)NC(=S)N1</smiles>

6za, $31 \%$

Scheme 2: Aldehyde substrate scope of three-component reaction of aldehydes, thiourea and trimethyl orthoformate. Reactions were performed with aldehydes ( $1.0 \mathrm{mmol}, 1.0$ equiv), thiourea $\left(2.5 \mathrm{mmol}, 2.5\right.$ equiv), trimethyl orthoformate $\left(1.0 \mathrm{mmol}, 1.0\right.$ equiv) in $1 \mathrm{~mL} \mathrm{DMF}$ at $80{ }^{\circ} \mathrm{C}$ for $5 \mathrm{~h}$; yields refer to isolated yields.

yield $(2.06 \mathrm{~g})$. This result was similar to that obtained on a smaller scale (Scheme 4).

All synthesized compounds were isolated by column chromatography and characterized by detailed spectroscopic analyses.
To further verify the structure unambiguously, as a representative example, the structure of 6aa was also confirmed by single crystal X-ray diffraction (XRD) studies after crystallization from ethyl acetate/hexane (Figure 2). CCDC 1991859 (for 6aa) contains the supplementary crystallographic data for this paper. 


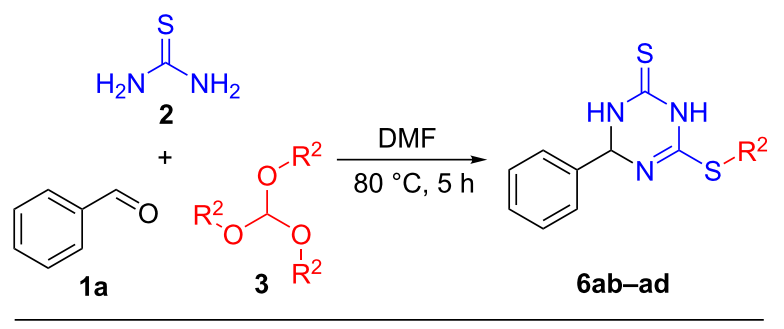<smiles>CCSC1=NC(c2ccccc2)NC(=S)N1</smiles><smiles>CCPSC1=NC(c2ccccc2)NC(=S)N1</smiles>

6ab, $38 \%$<smiles>CCCCOSC1=NC(c2ccccc2)NC(=S)N1</smiles>

6ad, $40 \%$

Scheme 3: Orthoformate substrate scope of the three componen reaction of benzaldehyde, thiourea, and orthoformates. Reactions were performed with benzaldehyde ( $1.0 \mathrm{mmol}, 1.0$ equiv), thiourea (2.5 mmol, 2.5 equiv), orthoformates ( $1.0 \mathrm{mmol}, 1.0$ equiv) in $1 \mathrm{~mL}$ DMF at $80^{\circ} \mathrm{C}$ for $5 \mathrm{~h}$; yields refer to isolated yields.<smiles>COC(OC)OC(OC)C(=O)O</smiles><smiles>CSC1=NC(c2ccccc2)NC(=S)N1</smiles>

6aa, $2.06 \mathrm{~g}, 87 \%$

Scheme 4: Gram-scale synthesis of $6 a a$

These data are provided free of charge by The Cambridge Crystallographic Data Centre.

To gain insights into the mechanistic pathway, a series of preliminary experiments were performed. First, the reaction of benzaldehyde (1a) and thiourea (2) in DMF at $80{ }^{\circ} \mathrm{C}$ produced $1,1^{\prime}$-(phenylmethylene)bis(thiourea) (4) together with its ring closure product 7 (Scheme 5a). It is worth mentioning that reacting compound 7 with trimethyl orthoformate (1.0 equiv) under the optimized conditions for $5 \mathrm{~h}$ furnished product $6 \mathbf{6 a}$ in only $35 \%$ yield (Scheme $5 b$ ). On the other hand, repeating the same reaction in the presence of thiourea (1.0 equiv) afforded

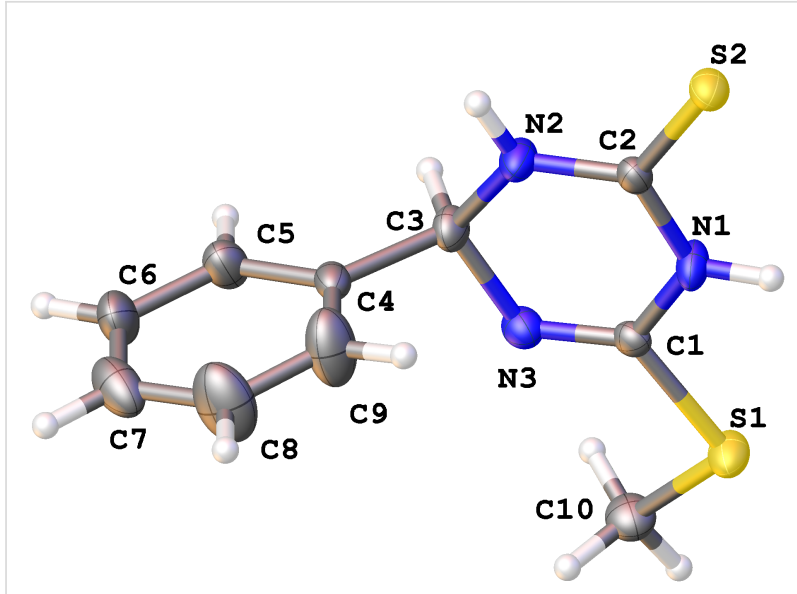

Figure 2: X-ray structure of 6-(methylthio)-4-phenyl-3,4-dihydro-1,3,5triazine-2 $(1 H)$-thione $(6 \mathrm{aa})$ with thermal ellipsoids at $50 \%$ probability (CCDC 1991859).

product 6aa in 95\% yield (Scheme 5c), thereby indicating the crucial participation of thiourea in this alkylation process. Pleasingly, thiourea (2) upon heating in DMF with trimethyl orthoformate (3a, 1.0 equiv) yielded formylthiourea in $62 \%$ yield after $5 \mathrm{~h}$, thus indicating that it is involved in the methylation reaction mechanism (Scheme 5d).

Based on previous literature reports and our experimental observations, a plausible mechanism for the synthesis of $\mathbf{6}$ is proposed in Scheme 6. Initially, the reversible nucleophilic attack of thiourea $\mathbf{2}$ on aldehyde $\mathbf{1}$ forms imine $\mathbf{8}$. Then, a nucleophilic addition of another molecule $\mathbf{2}$ takes place to furnish the tricomponent adduct $\mathbf{4}$, which undergoes elimination of ammonia to afford the corresponding ring-closed intermediate 7 [37]. The latter undergoes a proton-transfer process to form intermediate 10 [38]. Thereafter, the subsequent step involves the reaction of trialkyl orthoformate $\mathbf{3}$ with thiourea (2) to produce imidate intermediate $\mathbf{9}$, which is nucleophilically attacked by intermediate $\mathbf{1 0}$ and transfers the alkyl group $\mathrm{R}^{2}$ to deliver the alkylated intermediate 11. Meanwhile, $N, N$-dimethylformamide dialkyl acetal might also play a role in this alkylation process [39]. Finally, proton transfer processes afford the desired product 6 and byproduct 5 .

\section{Conclusion}

In summary, we have developed a simple and efficient method for the synthesis of 4-aryl-6-(alkylthio)-3,4-dihydro-1,3,5triazine-2 $(1 H)$-thiones through a catalyst-free multicomponent reaction. The products were obtained in moderate to good yields by the one-pot reaction of substituted aldehydes, thiourea, and trialkyl orthoformates. The strategy exhibits the use of inexpensive and easily available reagents and substrates to afford the targeted substituted triazinethione derivatives. 
(a)<smiles>O=Cc1ccccc1</smiles>

$1 a$<smiles>NC(N)=S</smiles>

2<smiles>COC(C)(C)O[Na]</smiles>
$80^{\circ} \mathrm{Ch}$<smiles>NC(=S)NC(NC(N)=S)c1ccccc1</smiles>

$4,12 \%$<smiles>S=C1NC(=S)NC(c2ccccc2)N1</smiles>

$7,25 \%$

(b)
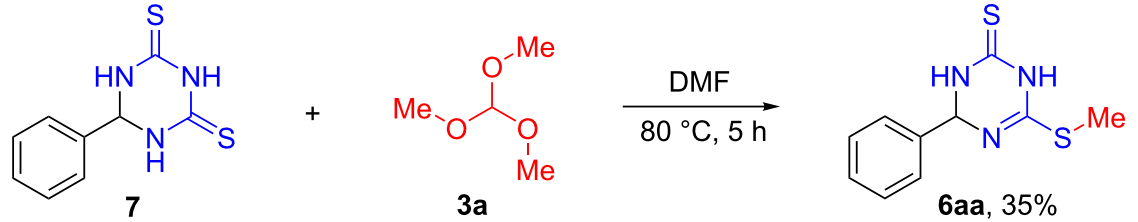

(c)

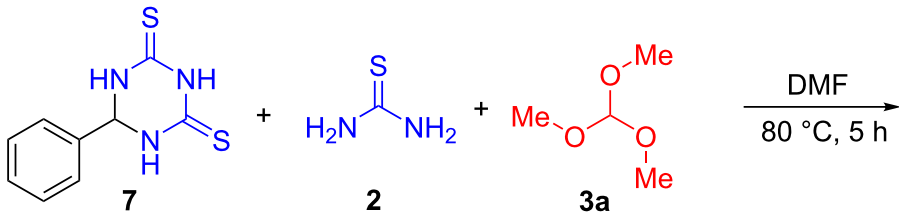<smiles>COC(=O)OCCCCCOC(C)(C)C</smiles>

(d)

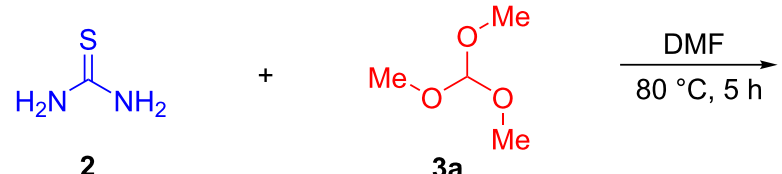<smiles>NC(=S)NC=O</smiles>

5, $62 \%$<smiles>O=Cc1cccc[Y1]1I</smiles><smiles>NC(=S)NCCO</smiles><smiles>NC(=S)N=Cc1ccccc1</smiles><smiles>NC(=S)NC(NC(N)=S)c1ccccc1</smiles><smiles>[R1]SC1=NC(c2ccccc2[Z17])NC(=S)N1</smiles><smiles>C[In]C</smiles><smiles>[R]SC1=NC(c2ccccc2)NC(=S)N1</smiles>

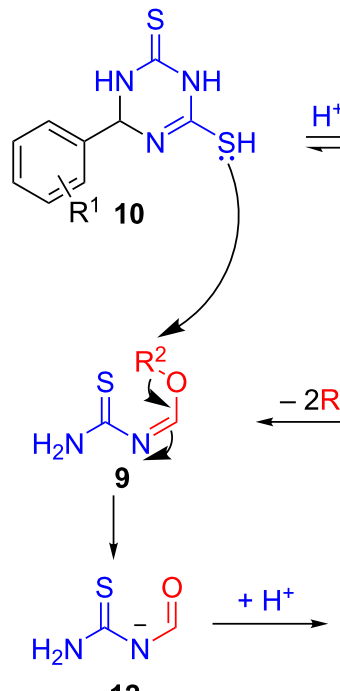<smiles>[13CH3]I</smiles><smiles>[R17]c1ccccc1C1NC(=S)NC(=S)N1</smiles><smiles>[R]OC([R])O[R]</smiles><smiles>NC(=S)NC=O</smiles>

Scheme 6: Plausible mechanism. 


\section{Supporting Information}

Supporting information features experimental procedures, characterization data, copies of NMR spectra and crystallographic data.

\section{Supporting Information File 1}

Experimental procedures, characterization data, copies of NMR spectra and crystallographic data.

[https://www.beilstein-journals.org/bjoc/content/ supplementary/1860-5397-16-120-S1.pdf]

\section{Supporting Information File 2}

Crystallographic information file of compound 6aa. [https://www.beilstein-journals.org/bjoc/content/ supplementary/1860-5397-16-120-S2.cif]

\section{ORCID ${ }^{\circledR} \mathrm{iDs}$}

Gui-Feng Kang - https://orcid.org/0000-0002-2196-4621 Gang Zhang - https://orcid.org/0000-0003-0774-5710

\section{References}

1. Liu, J.-K. Chem. Rev. 2005, 105, 2723-2744. doi:10.1021/cr0400818

2. Subramanian, P.; Rudolf, G. C.; Kaliappan, K. P. Chem. - Asian J. 2016, 11, 168-192. doi:10.1002/asia.201500361

3. Joule, J. A. Adv. Heterocycl. Chem. 2016, 119, 81-106. doi:10.1016/bs.aihch.2015.10.005

4. Wei, L.; Shen, C.; Hu, Y.-Z.; Tao, H.-Y.; Wang, C.-J. Chem. Commun. 2019, 55, 6672-6684. doi:10.1039/c9cc02371b

5. Jackowski, A.; Zones, S. I.; Hwang, S.-J.; Burton, A. W. J. Am. Chem. Soc. 2009, 131, 1092-1100. doi:10.1021/ja806978f

6. Dalinger, I. L.; Kormanov, A. V.; Suponitsky, K. Y.; Muravyev, N. V.; Sheremetev, A. B. Chem. - Asian J. 2018, 13, 1165-1172. doi:10.1002/asia.201800214

7. Vitaku, E.; Smith, D. T.; Njardarson, J. T. J. Med. Chem. 2014, 57, 10257-10274. doi:10.1021/jm501100b

8. Banerjee, R.; Pace, N. J.; Brown, D. R.; Weerapana, E. J. Am. Chem. Soc. 2013, 135, 2497-2500. doi:10.1021/ja400427e

9. Lim, F. P. L.; Dolzhenko, A. V. Eur. J. Med. Chem. 2014, 85, 371-390. doi:10.1016/j.ejmech.2014.07.112

10. Saczewski, F.; Maruszak, M.; Bednarski, P. J. Arch. Pharm. (Weinheim, Ger.) 2008, 341, 121-125. doi:10.1002/ardp.200700176

11. Ismail, A. M.; El Sayed, S. A.; Butler, I. S.; Mostafa, S. I. J. Mol. Struct. 2020, 1200, No. 127088. doi:10.1016/j.molstruc.2019.127088

12. Aly, A. A. J. Chin. Chem. Soc. 2007, 54, 437-446. doi:10.1002/jccs.200700061

13. Golankiewicz, B.; Januszczyk, P.; Ikeda, S.; Balzarini, J.; De Clercq, E. J. Med. Chem. 1995, 38, 3558-3565. doi:10.1021/jm00018a015

14. Wang, Q.; Liu, G.; Shao, R.; Huang, R. Heteroat. Chem. 2003, 14, 542-545. doi:10.1002/hc.10189
15. Akahoshi, F.; Takeda, S.; Okada, T.; Kajii, M.; Nishimura, H.; Sugiura, M.; Inoue, Y.; Fukaya, C.; Naito, Y.; Imagawa, T.; Nakamura, N. J. Med. Chem. 1998, 41, 2985-2993. doi:10.1021/jm970759u

16. Ogura, H.; Takahashi, H.; Sato, O. Chem. Pharm. Bull. 1981, 29 1838-1842. doi:10.1248/cpb.29.1838

17. Abdel Hamid, A. M. J. Iran. Chem. Soc. 2019, 16, 1853-1861. doi:10.1007/s13738-019-01659-6

18. Fairfull, A. E. S.; Peak, D. A. J. Chem. Soc. 1955, 803-808. doi:10.1039/jr9550000803

19. Müller, T. J. J., Ed. Multicomponent Reactions I; Science of Synthesis; George Thieme Verlag: Stuttgart, Germany, 2014.

20. Müller, T. J. J., Ed. Multicomponent Reactions II; Science of Synthesis; George Thieme Verlag: Stuttgart, Germany, 2014.

21. Zhu, J.; Wang, Q.; Wang, M.-X., Eds. Multicomponent Reactions in Organic Synthesis; Wiley-VCH Verlag GmbH: Weinheim, Germany, 2015. doi:10.1002/9783527678174

22. Dömling, A.; Wang, W.; Wang, K. Chem. Rev. 2012, 112, 3083-3135. doi:10.1021/cr100233r

23. Ochs, M.; Mayer, B.; Müller, T. J. J. Front. Chem. (Lausanne, Switz.) 2019, 7, No. 717. doi:10.3389/fchem.2019.00717

24. Vroemans, R.; Bamba, F.; Winters, J.; Thomas, J.; Jacobs, J.; Van Meervelt, L.; John, J.; Dehaen, W. Beilstein J. Org. Chem. 2018, 14, 626-633. doi:10.3762/bjoc.14.49

25. Rostamizadeh, S.; Aryan, R.; Ghaieni, H. R. Synth. Commun. 2011, 41, 1794-1804. doi:10.1080/00397911.2010.492460

26. Kavala, V.; Lin, C.; Kuo, C.-W.; Fang, H.; Yao, C.-F. Tetrahedron 2012, 68, 1321-1329. doi:10.1016/j.tet.2011.11.022

27. Ramos, L. M.; Guido, B. C.; Nobrega, C. C.; Corrêa, J. R.; Silva, R. G.; de Oliveira, H. C. B.; Gomes, A. F.; Gozzo, F. C.; Neto, B. A. D. Chem. - Eur. J. 2013, 19, 4156-4168. doi:10.1002/chem.201204314

28. Roy, D. K.; Tamuli, K. J.; Bordoloi, M. J. Heterocycl. Chem. 2019, 56, 3313-3323. doi:10.1002/jhet.3728

29. Smith, L. I.; Bayliss, M. J. Org. Chem. 1941, 6, 437-442. doi:10.1021/jo01203a009

30. Azizi, N.; Gholibeglo, E.; Babapour, M.; Ghafuri, H.; Bolourtchian, S. M. C. R. Chim. 2012, 15, 768-773. doi:10.1016/j.crci.2012.06.011

31. Neumann, D. M.; Cammarata, A.; Backes, G.; Palmer, G. E.; Jursic, B. S. Bioorg. Med. Chem. 2014, 22, 813-826. doi:10.1016/j.bmc.2013.12.010

32. Karami, B.; Farahi, M.; Pam, F. Tetrahedron Lett. 2014, 55 , 6292-6296. doi:10.1016/j.tetlet.2014.09.114

33. Srinivasulu, A.; Shantharjun, B.; Vani, D.; Ashalu, K. C.; Mohd, A.; Wencel-Delord, J.; Colobert, F.; Reddy, K. R. Eur. J. Org. Chem. 2019, 1815-1819. doi:10.1002/ejoc.201900033

34. Janin, Y. L.; Chiki, J.; Legraverend, M.; Huel, C.; Bisagni, E. Tetrahedron 1999, 55, 12797-12804. doi:10.1016/s0040-4020(99)00755-3

35. Felicetti, T.; Cannalire, R.; Pietrella, D.; Latacz, G.; Lubelska, A.; Manfroni, G.; Barreca, M. L.; Massari, S.; Tabarrini, O.; Kieć-Kononowicz, K.; Schindler, B. D.; Kaatz, G. W.; Cecchetti, V.; Sabatini, S. J. Med. Chem. 2018, 61, 7827-7848. doi:10.1021/acs.jmedchem.8b00791

36. Liu, X.; Wang, W.; Zhao, Y.; Lai, D.; Zhou, L.; Liu, Z.; Wang, M. J. Nat. Prod. 2018, 81, 1803-1809. doi:10.1021/acs.jnatprod.8b00258

37. Rezaee, P.; Davarpanah, J. Res. Chem. Intermed. 2016, 42, 6815-6830. doi:10.1007/s11164-015-2376-8

38. Friot, C.; Reliquet, A.; Reliquet, F.; Meslin, J. C. Phosphorus, Sulfur Silicon Relat. Elem. 2000, 156, 135-149. doi:10.1080/10426500008044998 
39. Janin, Y. L.; Huel, C.; Flad, G.; Thirot, S. Eur. J. Org. Chem. 2002, 1763-1769.

doi:10.1002/1099-0690(200206)2002:11<1763::aid-ejoc1763>3.0.co;2 q

\section{License and Terms}

This is an Open Access article under the terms of the Creative Commons Attribution License

(http://creativecommons.org/licenses/by/4.0). Please note that the reuse, redistribution and reproduction in particular requires that the authors and source are credited.

The license is subject to the Beilstein Journal of Organic Chemistry terms and conditions:

(https://www.beilstein-journals.org/bjoc)

The definitive version of this article is the electronic one which can be found at:

doi:10.3762/bjoc. 16.120 